\title{
A produção da hereditariedade política canaca
}

\author{
Ana Crhistina Vanali ${ }^{1}$
}

O artigo de Éric Soriano "Le fils du chef : État colonial et production de l'hérédité politique en Nouvelle-Calédonie $»^{2}$ trata da Nova Caledônia que ocupa um lugar especial na história colonial francesa, por causa das negociações pelas configurações políticas elaboradas desde 1946. É um ano fundamental no império francês, pois corresponde à definição de novos estados institucionais, de modo a ter acesso a novos direitos para suas pessoas. De sujeitos e/ou nativos do império, grupos inteiros tornam-se cidadãos franceses, incluindo a possibilidade de votar e, acima de tudo, de ter posições políticas. Esta singular politização do antigo colonizado é uma das bases da Nova Caledônia contemporânea. Deve-se dizer que a Nova Caledônia está no cerne de um processo político de autodeterminação único no conjunto pós-colonial francês, que pode ser considerado como uma descolonização negociada, agendada pela assinatura do Acordo de Nouméa em $1998^{3}$.

Esse processo desde então tem encorajado a pesquisa histórica ${ }^{4}$, como a de Éric Soriano, que evidencia o desenvolvimento político e as trajetórias da Nova Caledônia ${ }^{5}$. A intenção é

\footnotetext{
${ }^{1}$ Doutora em Sociologia pela Universidade Federal do Paraná (UFPR). Pesquisadora do Núcleo de Estudos Paranaenses (NEP-UFPR). E-mail: anacvanali@yahoo.com.br

2 Texto original «Le fils du chef : État colonial et production de l'hérédité politique en Nouvelle-Calédonie», Critique internationale, vol. 73, № 4, 2016, p. 37-52. Disponível em https://www.cairn.info/revue-critique-internationale-2016-4-page-37.htm. Acesso 25.outubro.2017.

3 O Acordo de Nouméa de 1998 prevê transferir poder político para a Nova Caledônia e seus habitantes originais, os Canacos, até que o território decida se prefere permanecer como parte da França ou tornar-se um país independente, o que se dará em um referendo a ser realizado entre 2014 e 2019. A França irá continuar a controlar os assuntos militares, diplomáticos e monetários, a imigração e a polícia, até a realização do referendo, e posteriormente também, na hipótese da população optar pela permanência dos laços com a República Francesa. Este já é o segundo acordo firmado entre a Nova Caledônia e a França. O primeiro foi o Acordo de Matignon, de 5 de maio de 1988, assinado por Lionel Jospin. Já o Acordo de Nouméa foi referendado pela população do Território em 8 de novembro de 1998, com 72\% de aprovação. Fonte Radio New Zealand International. 14 de junho de 2009.
}

${ }^{4}$ Como as obras de Alban Bensa (Les sanglots de l'aigle pêcheur: Nouvelle-Calédonie, la guerre kanak de 1917, Comprendre I'identité kanak, Kanak: Portrait de Groupe, Nouvelle-Calédonie entre outros), Benoit Trépied (Une mairie dans la France coloniale. Koné, Nouvelle-Calédonie entre outras) ou Isabelle Merle (Expériences coloniales: la Nouvelle-Calédonie, 1853-1920 entre outros) 
compreender as abordagens particulares da situação colonial e seus legados. Esta é precisamente a maneira pela qual o mundo dos canacos conquistou esses novos poderes que Eric Soriano estuda em seu livro de 2014. Na encruzilhada da história, da antropologia e da ciência política, a pesquisa de Éric Soriano ${ }^{6}$ enfoca os impactos sociológicos do poder político e a reciprocidade entre a política e a sociedade. Pesquisador do Centro de Pesquisas Sociológicas e Políticas em Paris (CSU/CRESPPA) e no Centro de Estudos Comparados e Pesquisa em Etnologia (CERCE), Soriano tornou-se conhecido pelo público em geral a partir de 2007 , comentando sobre a criação do Ministério da Identidade Nacional pelo governo de Sarkozy através de conferências e analisando as novas formas de discurso racista7. No processo, ele também foi signatário do tribuno ${ }^{8}$ do Comitê de Vigilância contra Usos da História (CVUH) ${ }^{9}$.

Em sua tese de doutorado, o autor utiliza fontes de primeira mão como as entrevistas com políticos canacos, realizadas entre 1993 e 1998, além de um trabalho de campo meticuloso. A sequência de 1946-1976 em que o autor se concentra é marcada pelos esforços políticos do mundo dos canacos para defender o novo estatuto do cidadão francês, que veio com a revogação do decreto de indigenato, que levou ao surgimento de um nacionalismo canaco, que ainda é o fundamento político do arquipélago. A investigação de Soriano é inovadora na medida em que está situada na tensão entre o colonial e o político - que é a singularidade da Nova Caledônia e, por extensão, do mundo dos canaco. O que acontece quando o ex-colonizado se politiza com a ajuda da metrópole?

O artigo permite compreendermos a Nova Caledônia sem banalizá-la analisando questões estruturantes como "o que significa "fazer política" em um cenário onde a maioria dos

\footnotetext{
${ }^{5}$ Consultar além do artigo o livro SORIANO, Eric. La fin des Indigènes en Nouvelle-Calédonie. Le colonial à l'épreuve du politique. Paris: Karthala, 2014

${ }^{6}$ Consulte o site profissional de Erica Soriano: http://upvericsoriano.wordpress.com/. Acesso 24.dezembro.2017.
}

7 Consultar "Cultura e raça tornaram-se sinônimos". In: Mondomix, 10/02/2012. Disponível em http://www.mondomix.com/news/eric-soriano-le-mot-culture-racisme. Acesso 23.dezembro.2017.

${ }^{8}$ Ao lado de Catherine Coquery-Vidrovitch, Laurence De Cock, Marcel Dorigny, Olivier Le Troquer, Éric Mesnard, Gérad Noiriel, Michèle Riot-Sarcey e Pierre Schill. Era para alertar a excessiva instrumentalização da figura de Guy Môquet, da carta cuja leitura tinha sido obrigatória em 2007. La lecture de la lettre de Guy Môquet reste «obligatoire». Le Figaro, 19/10/2009. Disponível em http://www.lefigaro.fr/actualite-france/2009/10/19/01016-20091019ARTFIG00417-lettre-de-guy-moquet-les-profs-auront-carte-

blanche-.php. Guy Môquet: effacement de l'histoire et culte mémoriel. Disponível http://www.liberation.fr/tribune/2007/10/19/guy-moquet-effacement-de-l-histoire-et-culte-memoriel 104157

Acesso 29.dezembro.2017.

${ }^{9}$ Comité de vigilance face aux usages publics de l'histoire - (htt://cvuh.free.fr). 
relacionamentos mobilizados são estruturados na hereditariedade?" Esse estudo sobre a Nova Caledônia pode ser o ponto de partida para reflexões mais amplas sobre a questão colonial. A Nova Caledônia é uma sociedade exemplar de outras sociedades com colonização europeia e para defender uma abordagem localizada e se evitar qualquer generalização precipitada, temos estudos que demonstram configurações semelhantes no Brasil, nos Estados Unidos e na África do Sul.

A pesquisa de Soriano também é caracterizada pela atenção dada aos constantes aos processos de transformação da sociedade colonial. Várias questões incisivas destacam essas transformações como o desejo da metrópole de reinventar os laços com as sociedades locais. É principalmente na tentativa de se adaptar a contextos específicos que a ambiguidade permanece, que os termos da dominação colonial parecem querer ser mantidos. Refletindo sobre o futuro do canaco como cidadãos franceses, Soriano pergunta se os nativos podem ser cidadãos como os outros já que o decreto de nativos aplicado de 1887 a 1946 na Nova Caledônia, foi uma política de segregação social (a escolaridade foi apoiada pelas missões) e espacial (pelo estabelecimento de reservas e toques de recolher) para controlar populações colonizadas e prevenir possíveis revoltas.

Soriano mostra que na passagem do Estado indígena ao Estado cidadão, a ideia do plano republicano era construir um indivíduo fiel a família, a religião e a cultura para construírem a nação. A construção deste "cidadão" tem gradualmente confrontado na Nova Caledônia a experiência colonial, a conexão com a terra e os estatutos tradicionais propícios para a formulação do nacionalismo da década de 1970 (outro momento chave para a compreensão da Nova Caledônia). O "fim dos nativos" mostra que o colonialismo, na medida em que rompe com suas práticas, deve ser entendido em termos das estratégias utilizadas pelos grupos interessados para adquirir um sentido ao jogo do colonial e do estado pós-colonial. Este "sentido do jogo", constantemente renovado, também envolve complexas e dolorosas formulações de identidade. 